\title{
A preservação da água em um objeto de aprendizagem: saberes e possibilidades de ensino
}

\author{
Elsbeth Léia Spode Becker ${ }^{1}$ \\ Jussane Rossato ${ }^{2}$ \\ Anderson Ellwanger ${ }^{3}$
}

\begin{abstract}
RESUMO
Este artigo tem como objetivo apresentar um Objeto de Aprendizagem (OA) desenvolvido para mostrar o processo de produção de energia a partir da matriz 'água', sensibilizar para a sua preservação e registrar possibilidades de pesquisar em educação. O OA é destinado aos alunos do Ensino Básico e foi desenvolvido para complementar conteúdos curriculares sobre o tema envolvendo conteúdos de Física, Matemática e Geografia. A metodologia perpassou pela aprendizagem colaborativa e envolveu a multimodalidade de linguagem a partir da aula teórica, a música, o texto crítico e o $\mathrm{OA}$. O resultado obtido por meio de múltiplas ferramentas mostrou-se eficaz para abordar o tema mostrando possibilidades de reutilização da água nas ações cotidianas dos estudantes. Sobre os saberes e possibilidades de ensino discutidos por meio do OA, a investigação possibilitou atualizar demandas emergenciais para cuidar do planeta e multiplicar as formas de conexão de linguagens e de abordagens no ensino de Ciências.
\end{abstract}

PALAVRAS-CHAVE: Ensino de Ciências; Objeto de aprendizagem; Reutilização da água; Usina hidrelétrica.

\footnotetext{
1 Prof $^{\text {a }}$ Adjunta III - Ciências Humanas da Universidade Franciscana, Santa Maria, RS, Brasil - e-mail: elsbeth.geo@gmail.com

${ }^{2}$ Prof $^{\mathrm{a}}$ Adjunta III - Ciências Tecnológicas da Universidade Franciscana, Santa Maria, RS, Brasil - e-mail: jussaner@gmail.com

${ }^{3}$ Prof. Assistente III - Ciências Tecnológicas, da Universidade Franciscana, Santa Maria, RS, Brasil - e-mail: pfandd@gmail.com
} 
The preservation of water in a learning object: knowledge and possibilities of teaching

\begin{abstract}
This article aims to present a Learning Object (LO) developed to show the process of energy production from the 'water matrix', to sensitize for its preservation and to register possibilities of researching in education. The LO is intended for students of Basic Education and was developed to complement curricular contents on the subject involving contents of Physics, Mathematics and Geography. The methodology covered collaborative learning and involved the multimodality of language from the theoretical class, music, critical text and LO. The result obtained through multiple tools proved to be effective in addressing the theme by showing possibilities of reusing water in the daily actions of students. On the knowledge and teaching possibilities discussed through the LO, the investigation allowed to update emergency demands to take care of the planet and to multiply the forms of connection of languages and approaches in the teaching of Sciences.
\end{abstract}

KEYWORDS: Science teaching; Learning object; Water Reuse Hydroelectric plant.

\title{
Introdução
}

A água é a substância da vida no planeta Terra que, visto de longe, exibe o azul dos grandes oceanos. É também a fonte que inspira artistas, a rota dos navegantes que descobriram continentes inexplorados, o palco da aventura ou a base de ciclos econômicos. Tudo nasce, cresce, floresce e ampliase sob a bênção das águas.

Seus múltiplos significados fazem fluir o movimento incessante e a temporalidade da passagem, demarcando épocas e ciclos, erguendo civilizações ou abrigando rituais religiosos. A água regula a natureza com sua presença ou ausência. 
Ela está presente de várias formas no uso e nas atividades humanas e participa de todas as etapas da vida de cada ser e de todas as atividades econômicas dos países. $\mathrm{O}$ ser humano, além de consumir a água para viver, utiliza muita água para produzir alimentos (na agricultura e na pecuária), objetos de consumo (na indústria) e na comercialização (no transporte e na produção de energia).

É, portanto, importante apresentar o tema 'água como fonte da vida no planeta' e discutir os diferentes usos, entre eles, 'água como matriz de energia elétrica', para difundir saberes, em espaços formais e não formais de educação, e conscientizar sobre as possibilidades de uso e preservação.

A aquisição do conhecimento, ao longo da vida, está associada às diferentes experiências e situações de aprendizagem vivenciadas, desde cedo, no âmbito familiar, social e escolar. Os processos educativos escolares envolvem, necessariamente, a relação professor-aluno-conhecimento. "A partir dessas interações, o sujeito se apropria do saber escolarizado, da linguagem e dos padrões de comportamento que dão significado à vida" (BOER, 2009, p. 239).

Naturalmente, em cada instância social e em cada etapa da formação, cada um desses pilares tem diferentes pesos e papéis. Da escola, espera-se uma contribuição mais importante que das outras instâncias (família e sociedade) para o aprender a conhecer e o aprender a fazer. Isso requer a explicitação de objetivos formativos e metodologias para alcançá-los. É nesse contexto que os pressupostos deste artigo podem servir ao debate, ensejando propor e testar o uso de um Objeto de Aprendizagem (OA) sobre a água para a Educação Básica, refletindo sobre o impacto ambiental do uso da água como recurso energético. E, a partir da conscientização, criar as bases para sensibilizar para o uso racional da água com perspectivas de preservação e reutilização no âmbito doméstico e no uso individualizado como o ato de banhar-se no chuveiro com água quente proporcionada pela energia hidrelétrica. E, também, "irrigar" a pesquisa em educação com virtualidades ainda desconhecidas e conectá-las com o já conhecido e, dessa forma, gerar 
pensamentos reflexivos que registram as possibilidades de um outro mundo possível.

\section{Revisão de literatura}

\section{A água como matriz da vida no planeta}

A Terra, em sua evolução de aproximadamente 4,5 a 5 bilhões de anos, passou por inúmeras transformações e foram preciso milhões de anos para que sua estrutura se configurasse e pudesse oferecer condições para o desenvolvimento da vida.

Ao longo de sua formação, o planeta já possuiu diferentes características em consistência de rochas e minerais e, principalmente, em temperatura. A retrospectiva da evolução do planeta e do surgimento das primeiras formas de vida é uma importante reflexão para conceber a água como a matriz da vida no planeta.

A formação da Terra, em sua fase inicial, estava ligada a convulsões do magma incandescido, não abrigando nenhuma forma de vida. Passados milhões de anos, o planeta entrou em um processo de resfriamento gradativo. Essa alteração originou uma estreita camada de rocha ao redor da imensa "bola de fogo" e originou-se a litosfera (TEIXEIRA, 2003).

As mudanças na temperatura do planeta e o consequente resfriamento, fizeram com que fosse expelida, do interior da Terra, uma imensa quantidade de gases e vapor de água. Esse processo fez com que os gases formassem a atmosfera, e o vapor de água favoreceu o surgimento das primeiras precipitações. O longo período de chuva ocasionou a formação dos primeiros mananciais de águas, os oceanos primitivos (PRESS, 2006).

A formação dos oceanos foi fundamental para o surgimento da vida no planeta, pois a origem da vida veio dos seres aquáticos. Dessa forma, surgiram, primeiramente, na Terra, as bactérias e as algas, além de 
microrganismos, há cerca de 3 bilhões e 500 milhões de anos (BRANCO, 2003).

Essas primeiras formas de vida foram importantes para o surgimento de outros seres. Surgiram, então, oriundos dos microrganismos, os invertebrados, dentre eles, medusas, trilobitas, caracóis e estrela-do-mar. Além disso, desenvolveram plantas tais como as algas verdes. Todos os seres vivos, até esse momento, habitavam ambientes marinhos (BRANCO, 2003).

Algumas espécies de plantas marinhas desenvolveram a capacidade de se adaptar fora do ambiente aquático migrando para áreas continentais e, então, deram origem às primeiras plantas terrestres.

Os animais terrestres tiveram sua origem a partir do momento em que algumas espécies de peixes saíram da água dando origem aos anfíbios e, posteriormente, aos répteis. Houve um tempo no qual o planeta Terra ficou povoado por grandes répteis denominados dinossauros, caracterizando o Período Jurássico. O período Permiano deu origem às plantas com flores e os mamíferos. Os grandes répteis foram extintos há 70 milhões de anos (STRAHLER; STRAHLER, 2005).

Há mais ou menos 65 milhões de anos, teve início a formação das grandes cadeias de montanhas como o Himalaia e os Alpes. Os animais, como os mamíferos e as aves, proliferaram por todo o planeta e a atmosfera, a hidrosfera e a litosfera já possuíam as características atuais (STRAHLER; STRAHLER, 2005).

Então, há aproximadamente 4 milhões de anos, surgiram os ancestrais dos seres humanos. O planeta, a partir de então, entrou em períodos de muito frio, as glaciações, ocasionadas pelo crescimento e pelo recuo das geleiras. No entanto, há 11 mil anos as geleiras se fixaram nas zonas polares e, atualmente, abrigam a maior parte da água doce do planeta (STRAHLER; STRAHLER, 2005).

A água, portanto, foi um componente determinante para a introdução da vida no planeta. O músico e compositor, Guilherme Arantes, compôs uma canção de grande sucesso e chamou a Terra de 'Planeta Água'. Considerando 
a importância da água e sua dimensão, pode-se concordar com essa denominação. Para se ter uma ideia da importância da hidrosfera, basta lembrar que, dos $510.000 .000 \mathrm{Km}^{2}$ que constituem a área total da superfície da Terra, 73\% correspondem às porções líquidas mais importantes: oceanos e mares (TUNDISI, 2005).

O Brasil é um país rico em água; $81 \%$ do manancial hídrico brasileiro está na Bacia Amazônica, onde se concentram 5\% da população brasileira, e os 19\% no restante do país, onde vivem 95\% da população brasileira (BRANCO, 2003). O predomínio da energia hidrelétrica no país é explicado pelo imenso potencial hidráulico existente, decorrente de uma rede hidrográfica formada por bacias com rios volumosos, por causa de existência de clima quentes e úmidos (Clima Equatorial Úmido, Clima Tropical Típico e Clima Tropical Úmido). O relevo planáltico predominante no território brasileiro também beneficia esse quadro, pois origina desníveis acentuados ao longo dos cursos dos rios, fundamentais na produção de energia.

\section{A água como matriz energética no Brasil}

Entre os países industrializados, o Brasil possui a matriz energética considerada a mais renovável com $45,3 \%$ de sua produção proveniente de fontes como recursos hídricos, biomassa e etanol, para uso doméstico, agrícola, industrial e comercial. Porém, a matriz de energia elétrica brasileira, para abastecimento doméstico e industrial, conta com a participação de $86,1 \%$ da hidroeletricidade. A produção desse percentual é oriunda de 160 usinas hidrelétricas em operação, responsáveis por uma produção de, aproximadamente, 75 milhões de kW (MINISTÉRIO DE MINAS E ENERGIA, 2016). Esse fato é muito importante, pois a energia hidrelétrica é produzida de uma fonte renovável, no caso, a água dos rios, além de ser considerada uma fonte de energia limpa.

A maior parte da produção de energia hidrelétrica concentra-se na Região Sudeste, em virtude da grande quantidade de usinas nessa região, 
principalmente na bacia do rio Paraná, pois se trata da região de maior desenvolvimento econômico e de maior concentração populacional, onde ocorre, portanto, o maior consumo de energia do Brasil. Contudo, o maior potencial hidráulico brasileiro está na Amazônia, região de Clima Equatorial Úmido, de baixa concentração populacional, cuja demanda de energia ainda é pequena.

A utilização da eletricidade no Brasil começou a partir de 1881, quando foi instalado o primeiro sistema de iluminação pública do país, na área da Praça da República, na cidade de São Paulo. Em 1883, teve início o funcionamento da primeira usina hidrelétrica do Brasil, na cidade de Diamantina, em Minas Gerais. Mas a primeira grande companhia a explorar energia elétrica no Brasil foi a Light. Criada em 1889, no Canadá, essa empresa obteve a concessão do governo brasileiro para fornecer energia elétrica às cidades dos Estados de São Paulo e Rio de Janeiro e para instalar os bondes elétricos.

No século XX, o empresário Delmiro Gouveia construiu, no Nordeste brasileiro, a primeira usina hidrelétrica da região, utilizando a cachoeira de Paulo Afonso, situada no rio São Francisco. A eletricidade destinava-se ao abastecimento de uma fábrica de linhas construída no Sertão nordestino. Esse projeto serviu para convencer o governo de Getúlio Vargas das possibilidades hidrelétricas do rio São Francisco e para levar à assinatura, em 1945, do decreto que criava a Companhia Nacional Hidrelétrica do São Francisco (Chesf). Isso representou a primeira intervenção direta do governo federal na construção de uma hidrelétrica. Depois disso, foram criadas outras usinas, como a de Paulo Afonso e Sobradinho, na Bahia (BRANCO, 2002).

A construção da usina de Sobradinho formou um dos maiores represamentos de água no Brasil e inundou dezenas de povoados e quatro cidades. As pessoas que moravam nesses lugares foram transferidas para outros bem distantes e perderam parte de sua identidade histórica.

No fim da década de 1950, a deficiência de energia elétrica na região mais industrializada do País, que englobava os estados de São Paulo, Rio de 
Janeiro e Minas Gerais, motivou a construção da hidrelétrica de Furnas, no rio Grande, em Minas Gerais, pelo governo federal (BRANCO, 2002).

Em 1962, foi criada a empresa estatal Eletrobrás, responsável pelo Plano Geral de Eletrificação. Nesse plano, constavam o planejamento elétrico do país e a integração das regiões brasileiras. Assim, o abastecimento do território nacional foi dividido entre quatro grandes empresas subsidiárias da Eletrobrás: Eletronorte (com atuação na região Norte), Chesf (no Nordeste brasileiro), Furnas (nas regiões Sudeste e Centro-Oeste) e Eletrosul (na região Sul) (BRANCO, 2002)

Na década de 1960, surgiu a Companhia Energética de São Paulo S.A. (Cesp), que pôs em prática a construção de novas grandes usinas. No fim da década de 1970, essa empresa já fornecia $28 \%$ de toda a energia necessária no país. Nessa mesma década, foi construída, pelos governos do Brasil e do Paraguai, a Usina de Itaipu (BRANCO, 2002).

Portanto, no Brasil utiliza-se energia hidrelétrica desde o final do século XIX, mas os maiores investimentos ocorreram nas décadas de 1960 e 1970 e marcaram a fase de construção de grandes usinas, entre elas, a Usina de Itaipu, inaugurada em 1984. Essa usina foi construída a partir de um acordo binacional com o Paraguai e atualmente tem uma potência instalada de 14 mil MW, com 20 unidades geradoras. Essa capacidade é suficiente para suprir cerca de $80 \%$ de toda a energia elétrica consumida no Paraguai e de 20\% da demanda do sistema interligado brasileiro (GOLDENBERG; LUCOM, 2007).

A opção política por construir grandes usinas sempre foi, e continua sendo, criticada pelos ambientalistas e, também, por especialistas do setor energético, pelo fato de essa instalação provocar impactos socioambientais, como a submersão de grandes áreas onde antes existiam belezas naturais, flora, fauna, aldeias indígenas, comunidades agrícolas e cidades. O caso de Itaipu, no Rio Paraná, (entre o Brasil e o Paraguai), é representativo: o represamento do rio originou um enorme lago artificial que cobriu totalmente, em 1983, os famosos saltos de Sete Quedas, atração turística e paisagem 
natural de rara beleza, que a natureza levou milênios para construir. Além disso, o represamento do rio e a formação de um imenso lago sempre ocasionam um grande impacto ambiental, com a perda de solos agricultáveis, de flora e fauna locais, além da necessidade de remoção das populações ribeirinhas, que, muitas vezes, vivem na área há décadas ou séculos e dificilmente vão se adaptar em um novo lugar.

A partir da década de 1990, com o argumento de dinamizar o setor, o governo privatizou a maioria das empresas energéticas do país, sob a fiscalização da Agência Nacional de Energia Elétrica (Aneel). Mas os investimentos para aumentar a oferta de energia não acompanharam o crescimento do consumo, o que provocou uma grande crise de fornecimento em 2001. Na iminência de faltar energia, foi necessário introduzir, na ocasião, um rígido programa de racionamento Esse fato poderá ocorrer novamente, caso não se estabeleça um plano de desenvolvimento no setor que priorize a criação de usinas, a construção de redes de transmissão, entre outras medidas, como buscar outras matrizes energéticas, como a solar e a eólica (GOLDENBERG; LUCOM, 2007).

Nesse contexto, a partir de informações de ordem geral e específica sobre a água no planeta, como matriz da vida e como matriz energética, considera-se importante a abordagem do tema água pela escola. Tradicionalmente, a água é um tema de estudo das Ciências Naturais, mas, na atualidade, insere-se também como um conteúdo transversal trabalhado pela Educação Ambiental. Além disso, no espaço da escola, é preciso perceber e introduzir novas tecnologias as quais requerem novos Objetos de Aprendizagem OA).

\section{As tecnologias e os objetos de aprendizagem}

A sociedade do século XXI vivencia, cada vez mais, o uso massivo de tecnologias. A utilização de tecnologias exige, também, novos OA e isso perpassa por novas formas de comunicação. 
Toda forma de comunicação, seja escrita ou falada, e a produção de sentidos nelas inerentes são sócio historicamente situadas (BAKHTIN, 2003). Somos de certa forma reféns das nossas visões ou conceitos, ângulos sempre parciais que usamos para acessar o mundo. Nunca é possível compreender um texto isoladamente, fora de um contexto social e histórico, pois todo texto é construído em situações sociais específicas de uso da linguagem. Tampouco, em uma obra, os sentidos devem ser estabelecidos como se fossem construídos somente pela superfície verbal. É preciso perceber que as imagens (estáticas ou dinâmicas) e os sons são constituintes de uma obra e que, ao considerá-los, a elaboração dos sentidos tomará outros caminhos além daquele formado estritamente pelas palavras. Com isso, segundo Rojo; Moura (2012), os textos passam a ser entendidos como "modos de dizer" que não precisam ser exclusivamente escritos: podem também apresentar elementos visuais e sonoros ou acontecer de forma estática ou em movimento, como em OA. De acordo com Kalantzis; Cope (2006[2000]), isso constrói a multimodalidade dos textos, as quais instauram várias possibilidades de construção de sentidos.

Um OA pode ser trabalhado a partir de várias mídias que não somente a impressa e, algumas delas, mais próximas das atividades e das preferências cotidianas dos alunos, como exercícios que podem ser acessados pelos meios digitais da internet.

Os novos OA demandam interlocutores ainda mais críticos e conscientes dos processos discursivos de significação. Quando se trata de ser crítico no meio multimidiático tem-se que considerar, necessariamente, as tecnologias em fusão (textos, imagens, movimentos), hibridizadas, as quais geram mudanças de sentidos, ao manter a interdependência com uma sequência de imagens estáticas ou dinâmicas e de sons que remetem às alternativas significativas de escolhas e de reflexão.

É inegável o papel da escola no processo educativo mediante às necessidades emergenciais de mudanças de atitudes humanas para preservar a vida. É também urgente a revitalização escolar em seus recursos tecnológicos de ensino. Atualmente, vive-se diante do fato de que tanto em 
seus microcontextos, família e escola, como nas estruturas sociais mais amplas, locais e globais, os indivíduos têm sido fortemente influenciados pela presença da tecnologia. A partir disso, a escola encontra-se duplamente desafiada, tanto no compromisso de se (re)pensar frente às novas múltiplas linguagens e (multi)letramentos e a sua inserção e seu uso no ambiente escolar, quanto entender o processo de ensino-aprendizagem por meio das "novas" formas de educação, fazendo compreender as transformações e o verdadeiro papel do indivíduo na coletividade e frente à natureza.

Assim, o recurso de ensino multissemiótico ou multimodal, envolvendo diversas linguagens, mídias e tecnologias, é cada vez mais necessário, uma vez que atende o "novo aluno" de interesse colaborativo. Assim sendo, o melhor lugar para armazenar conteúdo para esse aluno é "nas nuvens" e a melhor maneira de se apresentarem é na estrutura ou formato de redes (hipertextos, hipermídias).

Dessa forma, o recurso de ensino multissemiótico ou multimodal e suas múltiplas linguagens podem contribuir ao debate preconizado pela UNESCO $^{4}$, como indica Delors (2010), que aponta a qualificação da Educação Básica como principal instrumento de democratização e de desenvolvimento humano, sintetizando quatro pilares para a educação do século XXI: aprender a conhecer (que está relacionado ao domínio das linguagens e da cultura), aprender a fazer (relacionado ao desenvolvimento de habilidades e à transformação do pensamento em ação), aprender a ser (à formação da identidade, à iniciativa e à autodisciplina) e aprender a conviver (à cooperação, à solidariedade, à sustentabilidade e à valorização das diferenças).

É nesse contexto que os pressupostos deste artigo ensejam mostrar um OA, associado ao som, a letra da música e ao texto crítico, ensejando seu uso como material didático sobre a água para a Educação Básica, criando as bases

\footnotetext{
${ }^{4}$ UNESCO - Organização das Nações Unidas para a Educação, Ciência e Cultura. No mundo, no Brasil
} 
para a cidadania crítica e colaborativa, especialmente, sobre recursos naturais e o uso racional da água.

\section{Metodologia}

O OA foi desenvolvido no Laboratório de Aprendizagem da Universidade Franciscana - UFN e supervisionado por três professores dessa instituição. Pretende mostrar o processo de energia a partir da matriz 'água' e gerar mudanças de sentidos, reflexivos, para a conscientização do impacto ambiental produzido por uma usina hidrelétrica e, principalmente, assumir o compromisso de minimizar os impactos sobre a água.

O OA proposto partiu da premissa "Você sabia que a água que existe no planeta é sempre a mesma"?

A metodologia adotada perpassou pela aprendizagem colaborativa que "se refere à abordagem instrutiva que estimula estudantes a trabalharem conjuntamente para atingir metas compartilhadas" (WILSON et al., 2013). $\mathrm{Na}$ presente atividade, a aprendizagem colaborativa envolveu a aula teórica (expositiva) sobre a água, o som (música), o texto crítico (impresso) e o OA (disponível em http://maisunifra.com.br/wp-content/uploads/objeto ANA/.

O OA pretendeu motivar a percepção por meio de imagens (estáticas ou dinâmicas) e de sons e assim despertar para a reflexão. Foi feita a testagem com um grupo de 20 alunos do Ensino Médio, sendo 10 alunos do Segundo Ano (Turma 201 do Instituto São José) e 10 alunos do Terceiro Ano (Turma 301 da mesma Escola), supervisionados pelos três professores da Universidade Franciscana - UFN e pela professora regente das turmas.

Em cada etapa, do uso do som, do texto e do OA foram realizados diálogos propositivos e críticos, que, em parte, constituíram os resultados deste artigo e contribuíram para pensar que há uma variedade de sujeitos e processos no mundo da educação que não cessam de brotar. Fazer escutar, então, os passos de um OA que conecta os sujeitos e suas vivências cotidianas 
ao ensino e à pesquisa em educação, é algo intrigante. Pesquisar e discutir a aplicação de um OA em sala de aula talvez seja ir por dentro da chuva, pelo meio de um oceano, sem guarda-chuva, sem barco. Pesquisar, então, é experimentar.

\section{Resultados e discussão}

Primeiramente, foi abordado o tema água, em aula teórica, mostrando sua importância como matriz da vida no planeta, regulando a natureza com sua presença ou ausência. A água também inspira os poetas, os escritores e os artistas. Nas letras, nos versos, na emoção humana irrompem muitos universos díspares provocadores de perplexidade, surpresas, temores, mas também de certa sensação de alívio e de liberdade do tédio. O som, a música (e a letra) despertam e descansam as sensações e os pensamentos humanos. Sentir e pensar a água, sua origem e seu destino, é aproximar o conteúdo dos livros didáticos ao mundo vivido. Assim, foi utilizado, como motivação inicial, o som, a música (e a letra) de 'Planeta Água' de Guilherme Arantes.

A letra da música de Guilherme Arantes apresenta a água como um elemento essencial à promoção da vida na Terra. E esse foi o principal propósito que motivou a presente proposta de estudo: pensar a água do ponto de vista de sua importância ambiental, mas, principalmente, dar-lhe significado em um OA.

QUADRO 1: 'Planeta Água'

\footnotetext{
Planeta Água

Água que nasce na fonte serena do mundo

E que abre um profundo grotão

Água que faz inocente riacho e deságua na corrente do ribeirão

Águas escuras dos rios que levam a fertilidade ao sertão

Águas que banham aldeias e matam a sede da população

Águas que caem das pedras no véu das cascatas, ronco de trovão

E depois dormem tranquilas no leito dos lagos, no leito dos lagos

Água dos igarapés, onde Iara, a mãe d'água é misteriosa canção

Água que o sol evapora, pro céu vai embora, virar nuvem de algodão
} 
Gotas de água da chuva, alegre arco-íris sobre a plantação

Gotas de água da chuva, tão tristes, são lágrimas na inundação

Águas que movem moinhos são as mesmas águas que encharcam o chão

E sempre voltam humildes pro fundo da terra, pro fundo da terra

Terra, planeta água, Terra, planeta água, Terra, planeta água

Água que nasce na fonte serena do mundo

E que abre um profundo grotão

Água que faz inocente riacho e deságua na corrente do ribeirão

Águas escuras dos rios que levam a fertilidade ao sertão

Águas que banham aldeias e matam a sede da população

Águas que movem moinhos são as mesmas águas que encharcam o chão

E sempre voltam humildes pro fundo da terra, pro fundo da terra

Terra, planeta água, Terra, planeta água, Terra, planeta água

Terra, planeta água, Terra, planeta água, Terra planeta água.

Fonte: Guilherme Arantes.

Uma das coisas mais fascinantes e mais difíceis de fazer no ensino e na pesquisa em educação talvez seja, mesmo, multiplicar as formas de conexão, de linguagens, de abordagens. Um OA assume-se implicado na criação e na invenção, ao pensar uma pesquisa das multiplicidades que faz gerar, igualmente, multiplicidades no ensino, oportunizando diferentes possibilidades de relações entre o objeto e o estudante. Além disso, permite entrelaçar múltiplas linguagens, textos, músicas, imagens, livros e, desta forma, permite promover rotas de escape do ensino tradicional.

$\mathrm{Na}$ sequência, por meio da leitura, foi feita uma contextualização da água como matriz da vida na Terra. E, também, foram evidenciados os diferentes estados físicos da água no cosmos, mas, na forma líquida, só é encontrada em grande quantidade na Terra. As grandes massas de água que compõem a hidrosfera, especialmente a água líquida dos oceanos, confere ao planeta Terra a cor azul. Esse aspecto ficou evidente aos humanos quando, pela primeira vez, a Terra foi vista do espaço, no início da década de 1960.

Ainda por meio da leitura, foi caracterizado o uso da água como matriz energética e apresentado um pequeno histórico da organização espacial das hidrelétricas brasileiras e uma pequena análise crítica da construção da Usina de Itaipu, a partir do texto 'Usina de Itaipu: uma estratégia geopolítica e economia' (ALBUQUERQUE; BIGOTTO; VITIELLO, 2010, p. 337). 
QUADRO 2: Usina de Itaipu: uma estratégia geopolítica e economia

\section{Usina de Itaipu: uma estratégia geopolítica e economia}

A construção da usina binacional Itaipu, mais do que uma necessidade econômica, representou uma estratégia política cujo objetivo era solucionar um impasse diplomático entre Brasil e Paraguai. Até então, esses países disputavam a posse da região do Salto de Sete Quedas. A usina de Itaipu foi uma tentativa de amenizar esse impasse; contudo, o acordo promoveu um desconforto nas relações com a Argentina, que temia que a construção da usina pudesse prejudicar seus direitos e interesses sobre as águas do rio Paraná, questão discutida na Assembleia da ONU, em 1972.

Em 1979, o impasse foi solucionado com o Acordo Tripartite, entre Brasil, Paraguai e Argentina, que estabeleceu regras para o aproveitamento dos recursos hidráulicos no trecho do rio Paraná, desde as Sete Quedas até a foz do rio da Prata. A construção da usina iniciou em 1973 e inaugurada em 1984, com a instalação de 14 comportas de vertedouro, potência de 1400 megawatts e 20 unidades geradoras de 700 megawatts cada uma.

De acordo com o tratado de construção da usina, cada país tem direito a $50 \%$ da energia produzida, e a energia não utilizada deve ser vendida ao sócio. O Brasil, além de consumir os $50 \%$ a que tem direito, compra do Paraguai, por meio da Eletrobrás, cerca de $45 \%$ da energia deste país.

O baixo preço que o Brasil pagava pela energia do país vizinho levou à assinatura de um novo acordo, em 2008, que elevou três vezes o preço da energia não usada pelo Paraguai. Outro ponto acertado nesse acordo é a não mediação da Eletrobrás, a partir de 2003 , sobre a venda desse excedente ao mercado brasileiro.

Fonte: ALBUQUERQUE; BIGOTTO; VITIELLO, 2010.

A partir dessa introdução, por meio da música, do texto e de sua leitura, utilizou-se o OA (figura 1), que foi testado com 20 alunos do Ensino Médio, na sala de informática da Escola. No primeiro momento, responderam e refletiram sobre a pergunta: 'Você sabia que a água que existe no planeta é sempre a mesma' (figura 1)? 
FIGURA 1: Planeta Terra - você sabia que a água que existe no planeta é sempre a mesma?

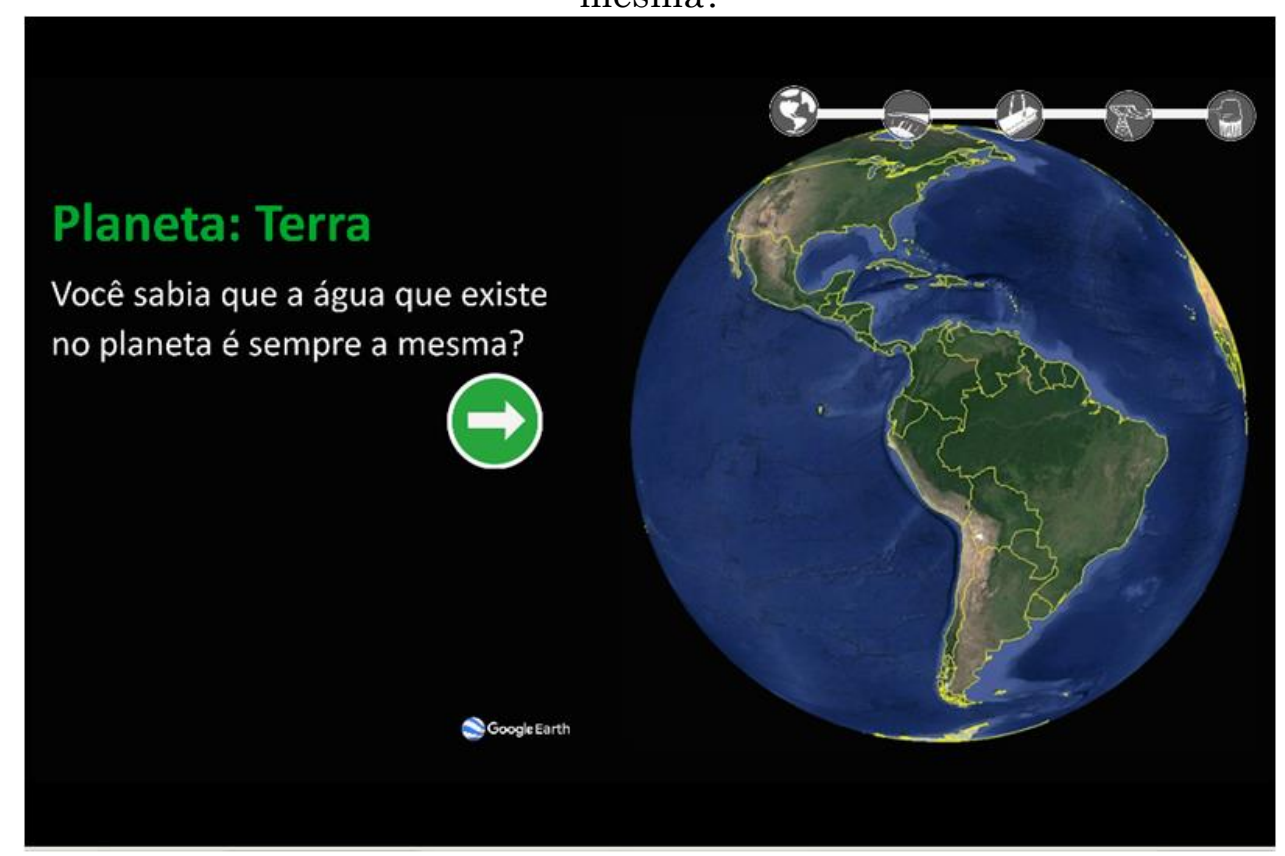

Fonte: http://maisunifra.com.br/wp-content/uploads/objeto_ANA/.

Para essa pergunta, apenas 10\% responderam que a água existente no planeta é sempre a mesma; 60\% responderam que a água está diminuindo; e 30\% asseguraram não saber, pois nunca pensaram nisso.

A partir dessa pergunta, pôde-se fazer algumas situações de reflexões, considerando informações e atitudes do cotidiano. Durante muito tempo acreditou-se que a água doce da Terra não acabaria nunca. Entretanto, o crescente aumento do número de habitantes do planeta, o crescimento das cidades sem um planejamento adequado, e, sobretudo, o desperdício e a poluição dos recursos hídricos reduziu e vêm reduzindo, cada vez mais, a disponibilidade de água para o consumo humano.

Apesar de sabermos que a água é fundamental para a vida humana, dos animais e vegetais, bem como para a realização das atividades agrícolas e industriais, o desperdício é evidente em várias situações: vazamentos, torneiras pingando, demora no banho e lavagem de carros e calçadas. Essas questões provam que a humanidade trata a água como um recurso inesgotável, embora muitos sofram com o racionamento e a disseminação de doenças em consequência do mau uso. 
Além do uso inadequado, a distribuição desigual dos recursos hídricos na superfície terrestre, assim como as desigualdades no consumo entre países e entre setores econômicos, torna o abastecimento de água ainda mais preocupante para as futuras gerações.

A humanidade precisa estar alerta de que a água limpa e potável pode acabar. Se isso acontecer, morrerão plantas, animais e o próprio ser humano, o principal responsável pela poluição e pelo desperdício da água. A partir disso, os alunos foram convidados a testar o $\mathrm{OA}$ e conheceram a localização da hidrelétrica de Itaipu (figura 2).

FIGURA 2: Localização da usina de Itaipu.

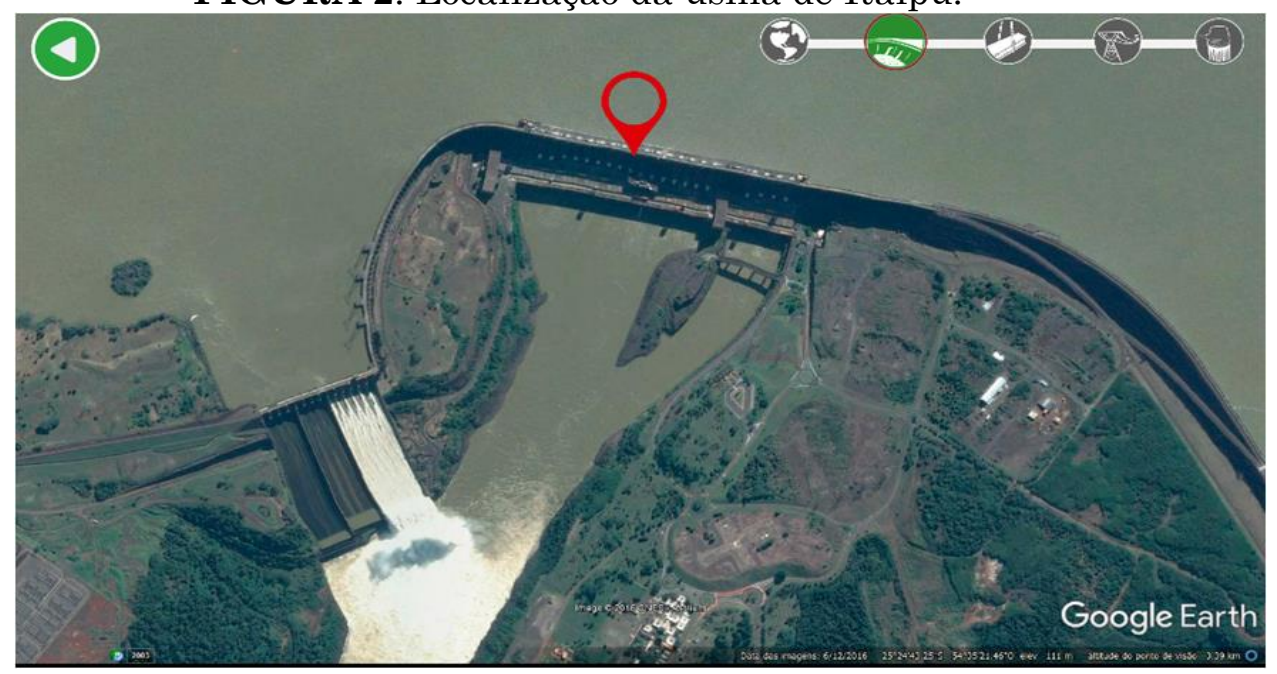

Fonte: http://maisunifra.com.br/wp-content/uploads/objeto_ANA/.

Na sequência, há informações: 'A) Reservatório', 'B) Peixes' e 'C) Clima' (basta clicar) e na 'Estrutura Interna' o aluno é convidado a abrir uma unidade didática de Física composta por: Introdução; Geração de energia elétrica; Transporte de Energia elétrica; Qual é a função dos transformadores?; Impactos Ambientais (figura 3). Nessa unidade, o aluno poderá se 'movimentar' por diversos conteúdos de Física e Matemática para, no final, saber o 'custo do seu banho'. 
FIGURA 3: Conteúdos de Física e de Matemática para saber o 'custo do banho'.

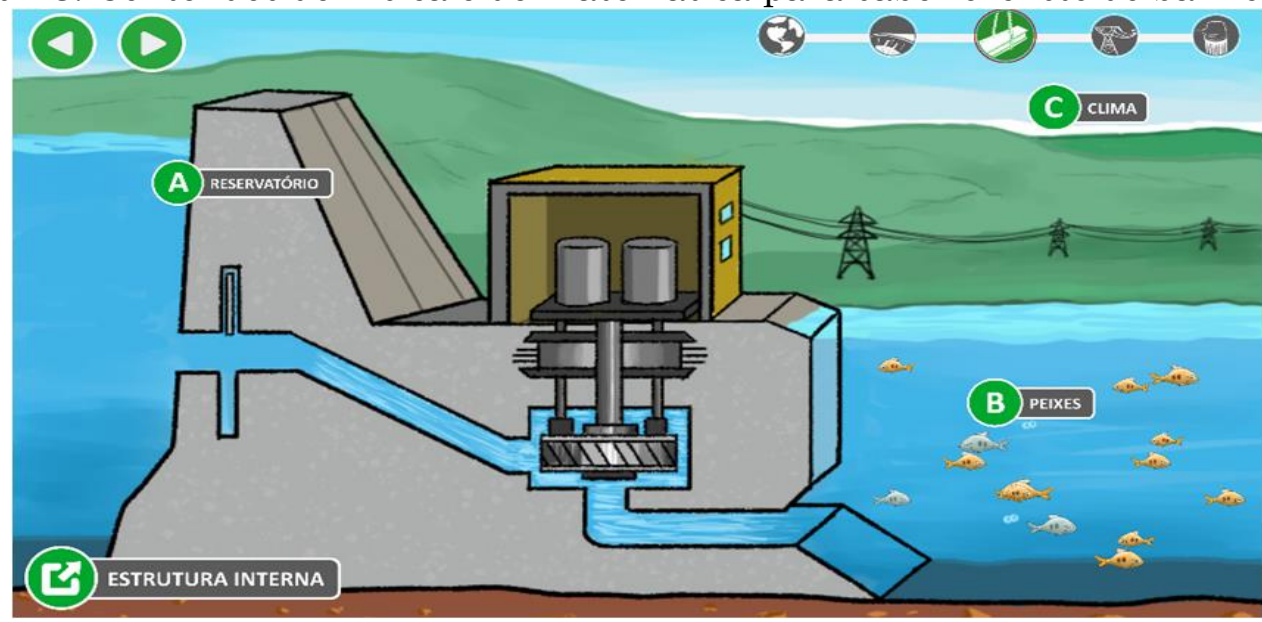

Fonte: http://maisunifra.com.br/wp-content/uploads/objeto_ANA/.

Em seguida, os alunos observaram a trajetória da energia elétrica que chega em suas residências por meio da simulação do 'Sistema de distribuição de energia elétrica desde a sua geração até o consumidor final'.

FIGURA 4: Sistema de distribuição de energia desde a sua geração até o consumidor final.

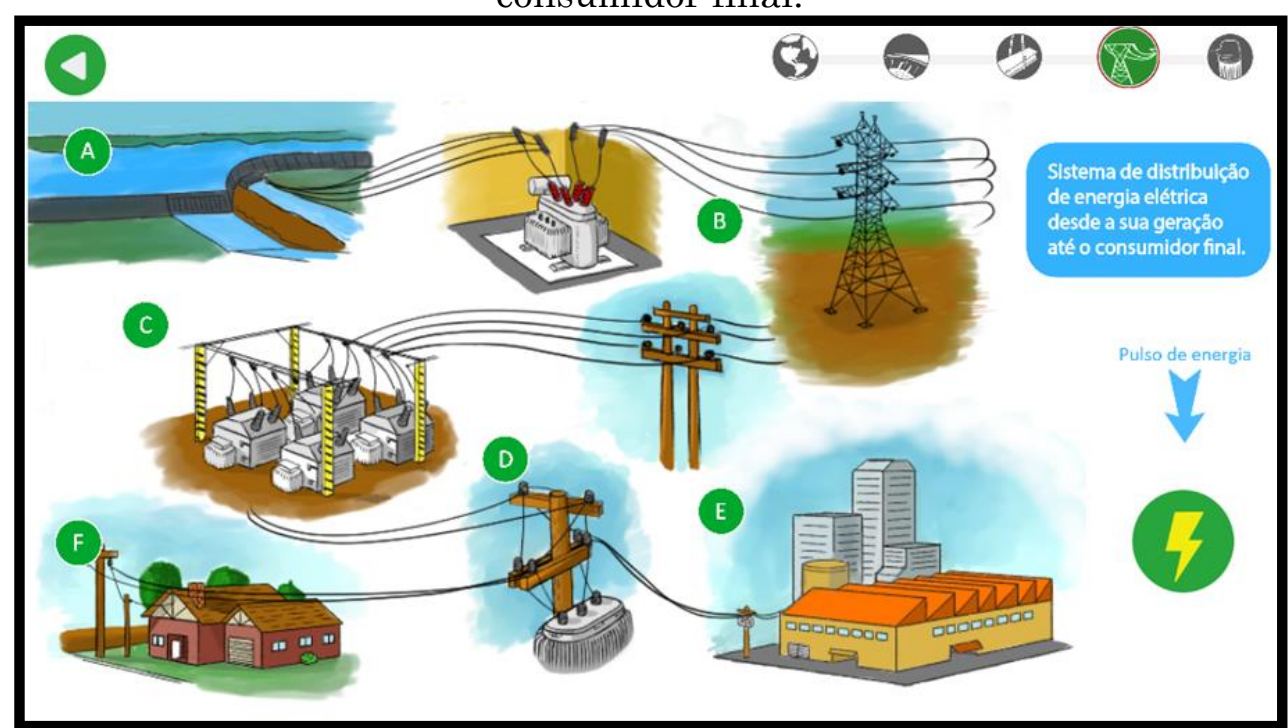

Fonte: http://maisunifra.com.br/wp-content/uploads/objeto_ANA/.

E, no final, os estudantes se depararam com a questão da reutilização da água do banho. Assim, o aluno foi defrontado com outra indagação: 'Você reutiliza a água do seu banho'? Para essa pergunta, 100\% dos alunos 
confirmaram que não reutilizam a água do banho e não imaginam como poderiam reutilizá-la.

FIGURA 5: O banho e as indicações de três maneiras (exemplos) de reutilização.

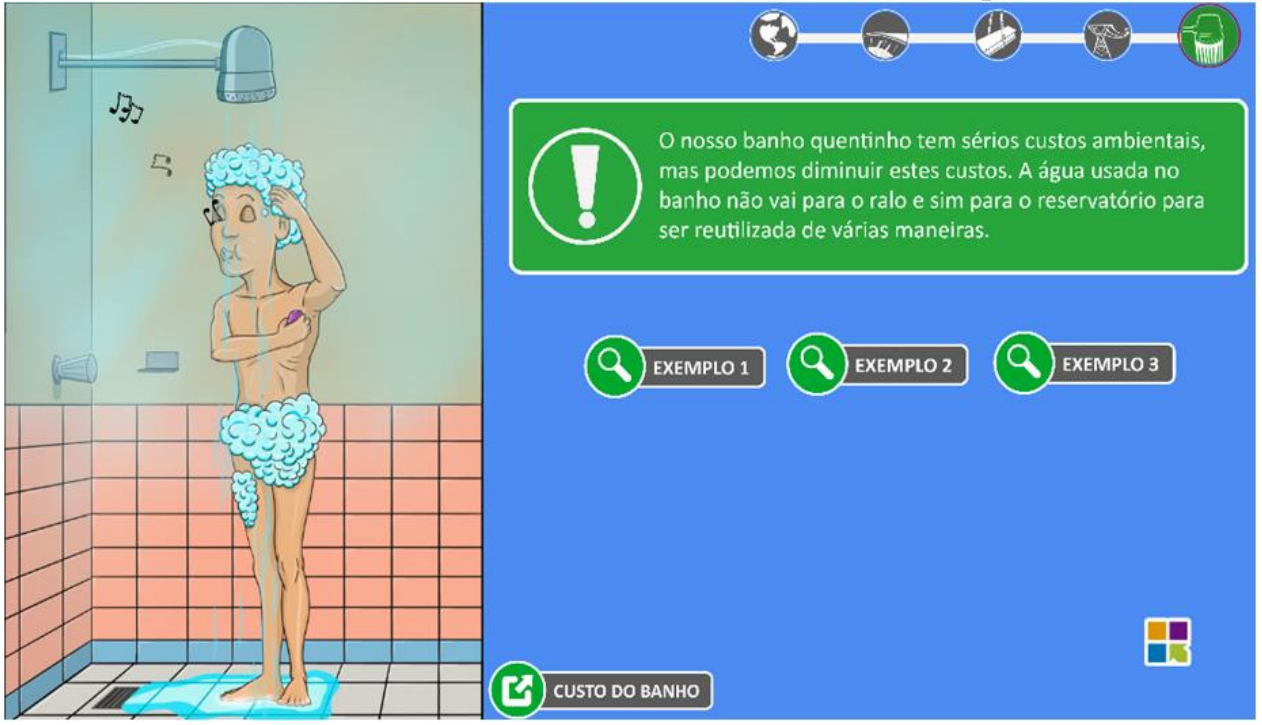

Fonte: http://maisunifra.com.br/wp-content/uploads/objeto_ANA/.

A partir daí, o OA levava a uma reflexão: "o nosso banho tem sérios custos ambientais, mas podemos diminuí-los. A água usada no banho não vai para o ralo e sim para o reservatório para ser reutilizada de várias maneiras", e indicava três exemplos (alternativas) (figuras 6, 7 e 8) para reaproveitá-la.

No OA, figura 6, após abrir a torneira, pode-se visualizar a água do reservatório ser reaproveitada para regar plantas de jardim. No OA, figura 7, após abrir a torneira, pode-se visualizar a água do reservatório ser reaproveitada para lavar carros e calçadas. Em ambas as telas, das figuras 6 e 7, tem-se: "Conclusão: existem algumas maneiras simples de cuidar do ambiente, um exemplo é a reutilização da água do banho e da máquina de lavar roupa. Essa água poderá ser reutilizada para regar as plantas do jardim e lavar calçadas e carros". 
FIGURA 6: Exemplo 1 de reutilização da água do banho, para regar plantas.

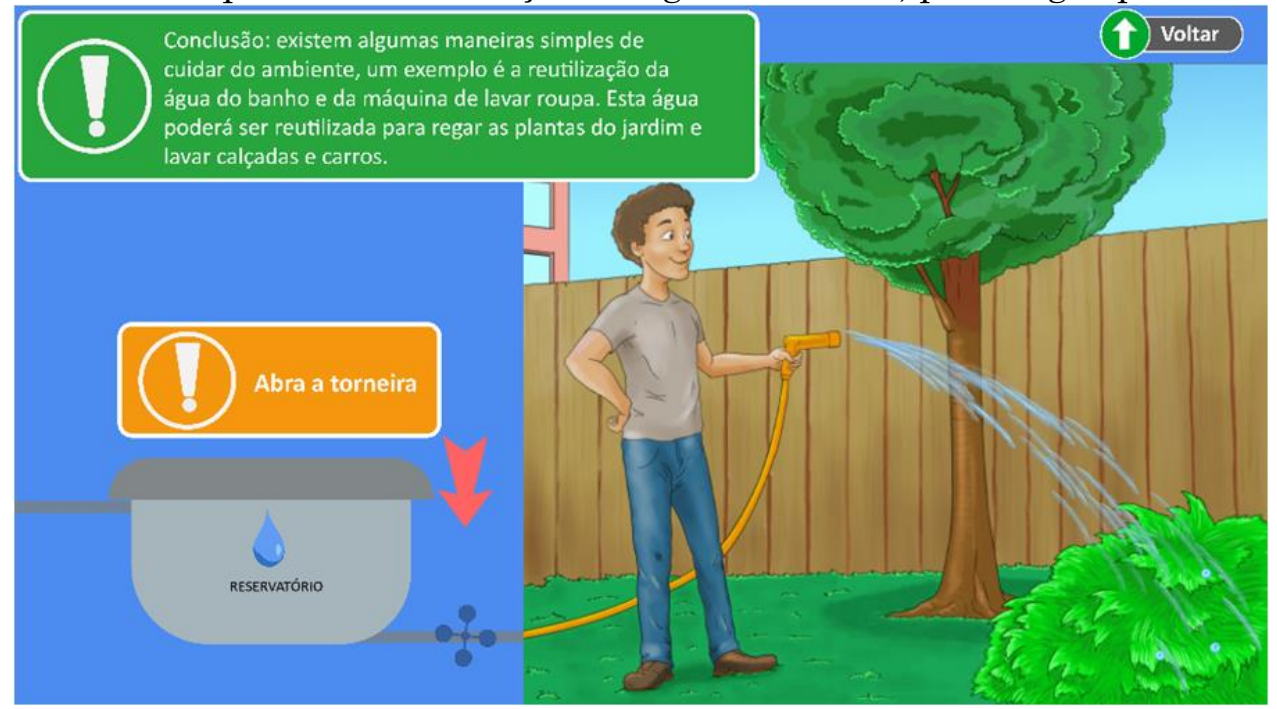

Fonte: http://maisunifra.com.br/wp-content/uploads/objeto_ANA/

FIGURA 7: Exemplo 2 de reutilização da água do banho, para lavar carros e calçadas.

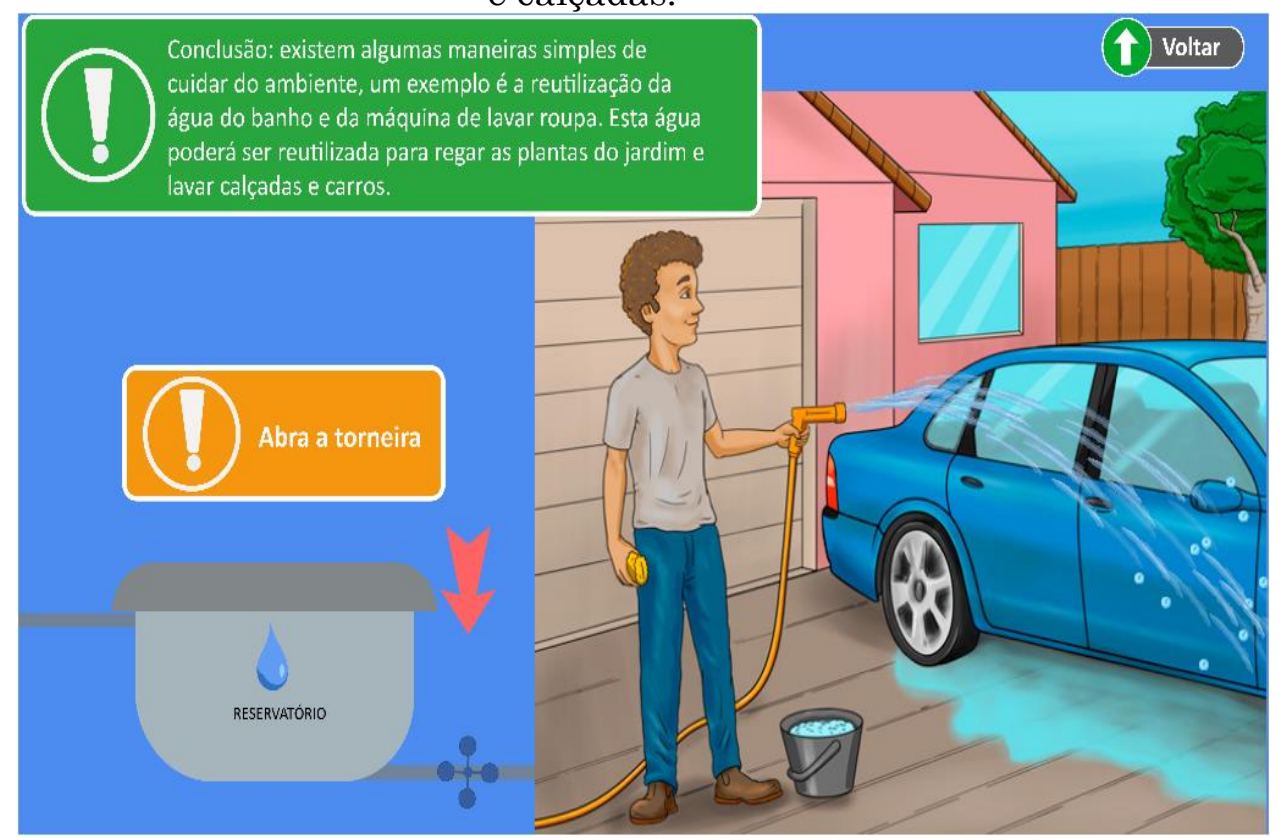

Fonte: http://maisunifra.com.br/wp-content/uploads/objeto_ANA/.

No OA, figura 8, após abrir a torneira, pode-se visualizar a água ser reaproveitada para abastecer o vaso sanitário, e, na tela, tem-se: "Conclusão: existem algumas maneiras simples de cuidar do ambiente, um exemplo é a reutilização da água do banho e da máquina de lavar roupa. Essa água poderá ser reutilizada para abastecer o vaso sanitário. 
FIGURA 8: Exemplo 3 de reutilização da água do banho, para abastecer a descarga do vaso sanitário.

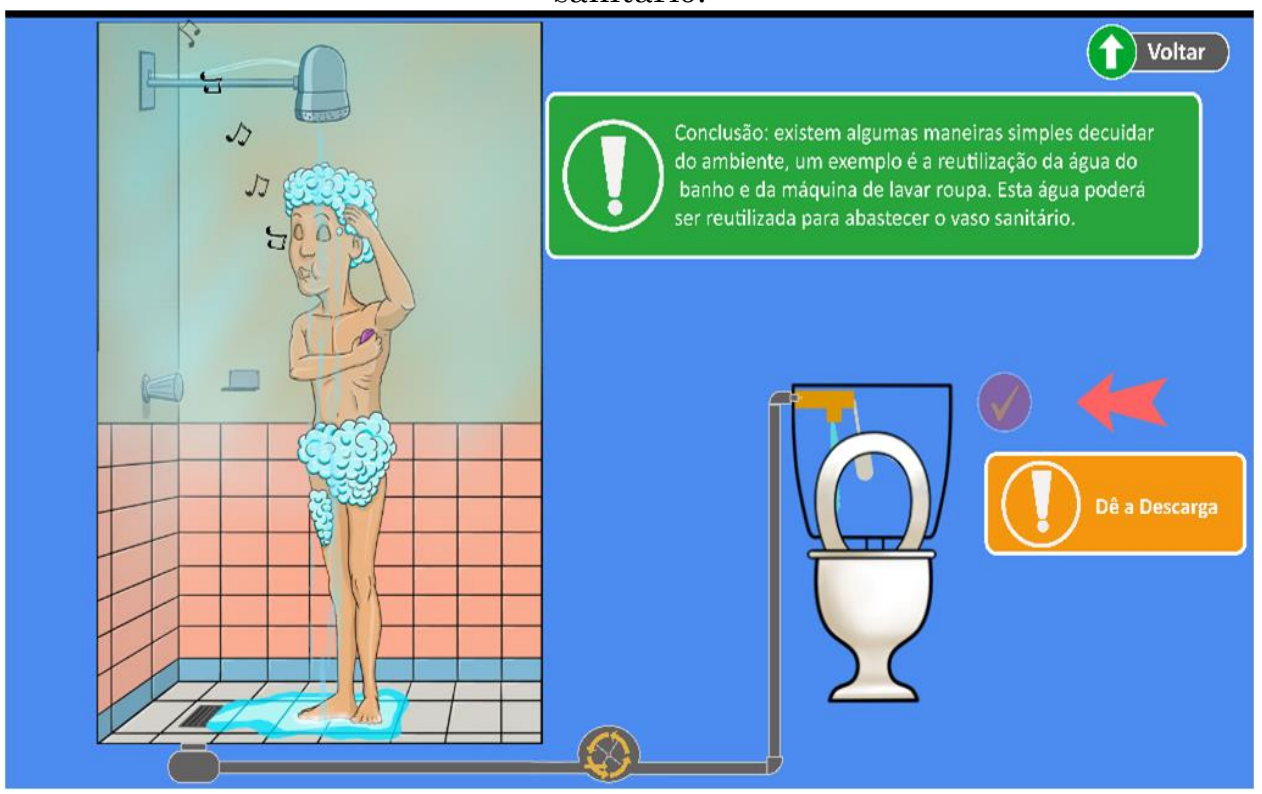

Fonte: http://maisunifra.com.br/wp-content/uploads/objeto_ANA/.

Os alunos que testaram o OA mostraram-se motivados com a possibilidade de reutilizar a água do banho e mostraram muito interesse na atividade, dizendo que o tema é instigante e que o uso de imagens com movimentos é excelente para manter a atenção e, assim, desenvolver o raciocínio. Já sobre calcular o custo do banho, 80\% dos alunos mostraram interesse no exercício e $20 \%$ acharam difícil. No entanto, segundo a aluna V.C.R.F., "achei legal, pois consegui relacionar as fórmulas da Física com a prática de ver a aplicação da fórmula na geração de energia”. Já o aluno L.F.M.S. afirmou que "achei muito legal e já sei que meu pai vai adorar mexer quanto ficar disponível. Isso é bom 'pra' mim, pois já tenho quem me ajude a estudar em casa também”. A estudante E. L. disse : "adorei fazer as opções para reaproveitar a água do banho e acredito que as alternativas podem, sim induzir, à reflexão para cuidar da água. Já a estudante E. D. ponderou: "achei os exercícios muito difíceis e gostei mais da parte que mostra como utilizar e poupar a água do banho”.

Os estudantes conheceram, interagiram e refletiram sobre a questão da água no planeta. Também conheceram o impacto ambiental produzido por uma usina hidrelétrica e visualizaram exemplos de reutilização da água do 
banho como forma de minimizar o custo do banho. Na concepção de Bakhtin (2013), o processo de significação somente ocorre quando compreendido pelas pessoas que estão interagindo e conforme o contexto que as envolve.

No movimento de interagir com o OA, o aluno, depara-se com coisas do seu cotidiano que o remetem à reflexão emergente, urgente e necessária sobre a vida no planeta e sobre a importância da água para a sua manutenção. $\mathrm{O}$ OA não abordou um tema novo, mas evidenciou um tema conhecido por meio de outras lentes e formas de visão sobre a realidade.

Estamos habituados aos métodos tradicionais de ver o mundo nos livros, nas imagens, nas mídias, nos conceitos por meio dos quais nos acostumamos a pensar o mundo, que esquecemos que esses conceitos não são a única forma de ver o mundo, mas apenas modos de recortá-lo, enquadrá-lo e, assim, tentar compreendê-lo, deixando sempre algo de fora ou que pode ser recortado por outro ângulo. Assim, pensar na água, sua importância para o planeta e despertar para o cuidado de preservá-la, é repensar nosso olhar sobre as relações entre sociedade e natureza.

Assim, um bom exercício para renovar nossa visão de mundo é, às vezes, trocar as lentes, para ver as mesmas paisagens com olhos diferentes. Podemos fazer isso utilizando novas linguagens por meio de um OA, criando, dessa forma, espaços para novos aprendizados e para a renovação de alguns de nossos pressupostos de vida.

Portanto, é inegável o papel da escola no processo educativo diante das necessidades emergenciais de mudanças de atitudes humanas para preservar a vida. É também urgente a revitalização escolar em seus recursos tecnológicos de ensino. Assim, o OA, multimodal, envolvendo diversas linguagens é cada vez mais necessário, uma vez que atende a "geração fluída" da Modernidade líquida.

\section{Conclusão}


A partir do exposto, concluiu-se que a composição multimodal, aula expositiva, som, texto e OA mostraram-se eficazes para abordar o tema água e, especialmente, induzir a reflexão para a preservação desse recurso natural.

Destaca-se que o OA é importante motivador de alunos jovens e tornase um excelente recurso didático para o Ensino Básico. Recomenda-se o uso deste OA para além da sala de aula formal. A utilização poderá se dar, também, em ambientes não-formais e informais de ensino. Por meio desse instrumento, o aluno e/ou o usuário pode conhecer algumas alternativas para reutilizar a água do banho. O resultado esperado é conscientizar para o "custo ambiental" inerente à produção de energia, bem como para a importância de "poupar" e preservar a água.

\section{Agradecimentos}

Agradecemos a Agência Nacional de Águas - ANA e a Coordenação de Aperfeiçoamento de Pessoal de Nível Superior - CAPES pelo apoio financeiro para o desenvolvimento do Objeto de Aprendizagem disponível em http://maisunifra.com.br/wp-content/uploads/objeto_ANA/.

\section{Referências}

ALBUQUeRQUE; M. A. M. de; BIGOTTO; J. F.; VITIELlO, M. A. Geografia Sociedade e Cotidiano. Ensino Médio Volume Único. São Paulo: Escala Educacional, 2010).

BAKHTIN, M. N. O problema do texto na linguística, na filologia e em outras ciências humanas. São Paulo: Martins Fortes, 2003.

BOER, N. A água nos conteúdos escolares: saberes e possibilidades de ensino. In: Água e educação: princípios e estratégias de uso e conservação. Org. RIGHES, A. A.; BURIOL, G. A.; BOER, N. Santa Maria: Centro Universitário Franciscano, 2009.

BRANCO, S. Energia e meio ambiente. São Paulo: Moderna, 2002.

BRANCO, S. Água, origem, uso e preservação. São Paulo: Moderna, 2003. 
BRASIL. Ministério da Educação e Cultura. Secretaria de Educação Fundamental. Parâmetros Curriculares Nacionais. Temas Transversais. Brasília: MEC/SEF, 1998.

DELORS, J. Educação: um tesouro a descobrir. Relatório para a Unesco da Comissão Internacional sobre educação para o século XXI. Brasília: UNESCO, 2010.

GOLDEMBERG, J.; LUCOM, O. Energia e meio ambiente no Brasil. Estudos Avançados. v.59, n.21, 2007.

KALANTZIS, M.; COPE, B. Changing the Role of Schools. In: COPE, B.; KALANTZIS, M. (orgs). Multiliteracies: Literacy Learning and the Design os Social Futures. New York: Routledge, 2006[2000], p. 121-148.

MINISTÉRIO DE MINAS E ENERGIA. Energia Hidráulica. Disponível em http://www2.aneel.gov.br/arquivos/pdf/atlas_par2_cap3.pdf. Acesso: 18 de Abril de 2018.

PRESS, F. et al. Para entender a Terra. São Paulo: Bookman, 2006.

ROJO, R.; MOURA, E. (Org). Multiletramentos na escola. São Paulo: Parábola, 2012.

ROJO, R. (Org.). Escola conectada: os multiletramentos e as TICs. São Paulo: Parábola, 2013.

STRAHLER, A. N.; STRAHLER, A. N. Geografia Física. Barcelona: Omega, 2005.

TEIXEIRA, W. et al. Decifrando a Terra. São Paulo: Oficina de textos, 2003.

TUNDISI, J. G. Água no século XXI, enfrentando a escassez. São Carlos: Rima, 2005.

WILSON, C. et al. Alfabetização midiática e informacional: currículo para formação de professores. Brasília: UNESCO, 2013.

Recebido em janeiro de 2018.

Aprovado em março de 2019. 